D.O.I.: $10.3895 / \mathrm{S} 1808-04482008000400012$

\title{
O TRADE-OFF ENTRE A FOLGA NA CAPACIDADE DE PRODUÇÃO E O NÍVEL DE ESTOQUE
}

\section{THE TRADE-OFF BETWEEN PRODUCTION CAPACITY BUFFER AND INVENTORY LEVELS}

\author{
Luiz Guilherme Sandrini ${ }^{1}$; Marco Aurélio de Mesquita ${ }^{2}$ \\ ${ }^{1}$ Universidade de São Paulo - USP - São Paulo - Brasil \\ lgsandrini@yahoo.com.br \\ ${ }^{2}$ Universidade de São Paulo - USP - São Paulo - Brasil \\ marco.mesquita@poli.usp.br
}

\begin{abstract}
Resumo
Este trabalho aborda o trade-off entre os custos do acréscimo de capacidade de produção e do aumento dos estoques de segurança, necessários para garantir um determinado nível de serviço no atendimento ao cliente. A partir de um modelo de simulação, implementado no software Arena, avalia-se a possibilidade de se utilizar estes recursos (buffer de capacidade e estoque de segurança) como substitutos para acomodar variações de demanda no sistema. No estudo, considera-se um sistema kanban constituido de uma única máquina (linha ou célula de produção) que produz um mix de dez produtos com demanda variável ao longo do tempo. Os resultados das simulações confirmam a melhoria do nível de serviço tanto pelo acréscimo de capacidade quanto pelo aumento dos estoques de segurança, sendo a opção mais vantajosa definida pela estrutura de custos considerada em cada caso.
\end{abstract}

Palavras-chave: trade-off; estoque; capacidade; simulação; buffer.

\section{Introdução}

O sistema kanban, utilizado para controlar a produção no chão de fábrica e limitar a quantidade de material em processo tem sido amplamente estudado, desde o primeiro artigo acadêmico publicado em 1977 (HOPP; SPEARMAN, 2004) até as muitas revisões bibliográficas mais recentes (BERKLEY, 1992; HUANG; KUSIAK, 1996; AKTURK; ERHUN, 1999; e KUMAR; PANNEERSELVAM, 2007). Trata-se de um tipo de sistema de controle de produção para ambientes de produção para estoque (MTS - Make-to-stock), no qual "o foco das atividades de gerenciamento da demanda é a manutenção de estoques de produtos acabados" (VOLLMANN et al., 2006, p.45). Dessa forma, o nível de serviço ao cliente acaba sendo determinado pela disponibilidade dos itens em estoque. 
O sistema kanban é um tipo de sistema puxado, já que este se baseia na demanda real, atuando na reposição dos estoques. Ele faz amplo uso de gestão visual, através de cartões e quadros (SIPPER; BULFIN, 1997). Freqüentemente, os quadros apresentam faixas com as cores verde, amarelo e vermelho, que indicam as prioridades de produção no chão de fábrica. Este sistema visual de quadros e cartões transmite as informações necessárias para o processo fornecedor repor seus estoques, o que só ocorre quando e se o consumo (demanda) de fato acontece.

Em vários trabalhos, as condições necessárias para a adequação e bom desempenho do sistema kanban são apresentadas. Sipper e Bulfin (1997, p.550) destacam que "o sistema trabalha de forma eficiente quando o fluxo é uniforme e o mix de produtos é estável”. Os autores ressaltam ainda que setups de máquina devem ser curtos, já que estes ocorrem freqüentemente, e que o sistema não funciona de forma satisfatória se o mix de itens ativos é muito grande.

Duggan (2002) salienta que nem todos os itens devem ser controlados por um sistema kanban, já que estes apresentam comportamentos de demanda distintos. Para o autor, os itens controlados por um sistema kanban devem ser os de alta demanda ou de consumo frequente. Os demais itens não deveriam dispor de pronta entrega, já que não são mantidos em estoque.

Além destes requisitos, a necessidade de estabilidade da demanda (baixa variação) é considerada determinante em seu desempenho. Monden (1981, p.30) afirma que "a variação da demanda deve ser inferior a 10\% para que o desempenho do sistema seja satisfatório". O autor não especifica se esse limite de variação refere-se a cada item ou variação no volume total de todos os itens. Marek et al. (2001, p.923) afirmam que "grandes variações no volume e mix de produtos destroem o fluxo de produção e prejudicam os objetivos de desempenho do sistema”. Já Takahashi et al. (2004, p.183) defendem que o sistema não se adapta a variações na demanda "grandes e repentinas".

A forma mais tradicional de proteção contra os efeitos das variações é o pulmão de peças (HURLEY; WHYBARK, 1999), utilizado para evitar a perda de fluxo de produção em recursos gargalo, conforme a teoria das restrições enfatiza. Além disso, são utilizados estoques de segurança de produtos acabados, de forma que quanto maior a variação da demanda, maiores os estoques necessários. Sipper e Bulfin (1997, p.550) chamam atenção para o fato de que "alta variação exige maior número de cartões kanban no sistema”, ou seja, maiores estoques.

Klassen e Menor (2007) ampliam a discussão ao propor a existência de um trade-off fundamental de processos, sendo constituído pela relação entre estoque, utilização de capacidade (folga de capacidade) e variabilidade, como mostrado na Figura 1. 
Figura 1 - Triângulo de gestão de processo.

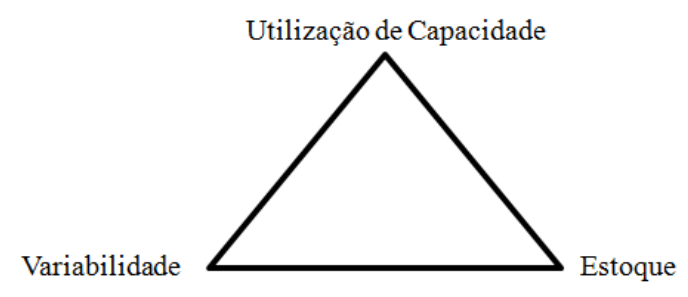

Fonte: Klassen e Menor (2007)

Segundo os autores, considerando um sistema sujeito a variação, o aumento da capacidade (redução da utilização) e o aumento do inventário são recursos substitutos com a função de prover melhor desempenho dos processos e serviços aos clientes, podendo ser combinados entre si. $\mathrm{O}$ trade-off se caracteriza pelo fato de que maiores níveis de capacidade exigiriam menores níveis de estoque, e vice-versa. Todas as iniciativas que visem a redução das variações, como estabilidade do processo, redução dos tempos de setup e quebras de equipamento (fontes de variação internas ao sistema), farão com que o sistema opere com menores níveis de capacidade e/ou estoque para garantir um bom nível de serviço.

De acordo com Hopp e Spearman (2004), a Toyota há muito tempo utiliza a capacidade de produção como forma de acomodar variações, através da realização de horas extras, sempre que as cotas de produção de um turno não forem atingidas no tempo normal de trabalho. Horas extras podiam ser realizadas já que as fábricas da empresa operavam em dois turnos, com folga de 4 horas entre o final de um turno e início do próximo. Assim, estoques de segurança podiam ser substituídos pelo aumento de capacidade, garantindo o nível de serviço desejado. Os autores consideram o uso de horas extras como um buffer de capacidade, buscando acomodar parte das variações de demanda

\section{Formulação do Problema: Estoque x Capacidade}

Klassen e Menor (2007), ao analisar o trade-off de processos citado acima, consideram dois cenários. O primeiro analisa o impacto de diferentes abordagens de intervenções de parada de máquina para manutenção, considerando diferentes freqüências e tempos de realização. Diferentes comportamentos de parada de máquina geram variações no sistema em diferentes níveis (HOPP; SPEARMAN, 2001). O segundo cenário realiza uma análise a partir de dados agregados da indústria, considerando registros de utilização da capacidade e mudança nos níveis de inventário. Neste segundo caso, vale ressaltar que outros fatores podem influenciar os resultados obtidos. 
Mapes (1993) avalia a relação entre as limitações de capacidade e a necessidade de estoque de segurança, num sistema empurrado responsável pela produção de um único item. A demanda é modelada seguindo uma distribuição normal de probabilidade, com diferentes níveis de risco de faltas. Os resultados mostram que quanto maior a capacidade de produção, menor a necessidade de estoques de segurança, e menores os riscos de falta nos estoques. Entretanto, o trabalho realizado pelo autor não contempla nenhuma análise de custo.

Garg et al. (2001), avaliam o trade-off entre o custo do aumento da flexibilidade e o custo do estoque, necessários para se atingir um determinado nível de serviço num sistema sujeito a variação. A análise proposta pelos autores é realizada considerando três cenários distintos. O primeiro e mais simples, para um sistema com um só tipo de produto, com uma linha dedicada. O segundo, para dois produtos, com linhas dedicadas, compartilhadas ou totalmente flexíveis, conforme ilustrado na figura 2. O terceiro é um estudo de caso para múltiplos itens e múltiplas linhas.

Figura 2 - Configuração para dois produtos num sistema de manufatura de estágio simples (single stage).

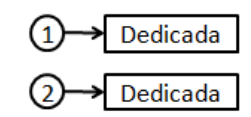

(a) Configuração dedicada

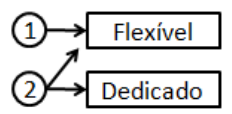

(b) Configuração parcialmente flexível

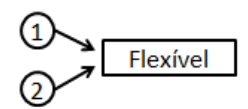

(c) Configuração flexível

Fonte: Garg et al. (2001)

O método de análise do trade-off proposto visa minimizar o 'Custo Total Relevante', que pode ser representado pela seguinte expressão:

\section{Custo Total Relevante $=$ Custo de manutenção dos estoques + Custo de capacidade adicional + Custo da flexibilidade de roteiro + Custo operacional adicional}

De acordo com os resultados apresentados pelos autores, o aumento das horas produtivas pode reduzir a necessidade de estoques de segurança, considerando um mesmo nível de variação. Entretanto, essa possibilidade nem sempre é vantajosa em termos de redução de custo. Em processos de capital intensivo (processos contínuos, siderúrgicos, etc) ou quando grandes investimentos são exigidos, a substituição de estoques por capacidade adicional deverá ser desvantajosa. No caso da manufatura repetitiva, objeto deste estudo, o custo dos materiais pode representar custo elevado frente ao uso de horas produtivas adicionais, tornando essa substituição uma alternativa eficiente e mais econômica (GARG et al., 2001). Além disso, o aumento do mix de produtos também gera aumento da necessidade de estoques de segurança, cenário no qual o uso de 
maior capacidade de produção pode apresentar maiores vantagens em termos de acomodação das variações do sistema.

\section{Objetivos da pesquisa}

O objetivo deste estudo, semelhante aos trabalhos de Klassen e Menor (2007), Mapes (1993) e parte do estudo proposto por Garg et al. (2001), consiste em analisar a relação entre as variáveis de processo (inventário, capacidade e variação) e a possibilidade destas serem substitutas em melhorar o nível de serviço ao menor custo. Entretanto, este estudo diferencia-se da proposta de Klassen e Menor (2007), já que o modelo a ser desenvolvido deverá considerar como fonte de variação a variação de demanda de cada item e a existência de um mix de produtos, ao invés de duas abordagens distintas de parada de máquina para manutenção.

Em relação ao trabalho de Garg et al. (2001), este estudo irá considerar somente uma linha responsável pela produção de um mix de produtos, ao invés de considerar um sistema com somente um produto. Ao considerar mais de um produto, os modelos propostos pelos autores contemplam a flexibilidade das linhas, fato que exigiria investimentos e outras linhas de produção, e que extrapola os objetivos deste trabalho. Mapes (1993), da mesma forma, realiza o estudo num cenário de produção empurrada, para somente um tipo de produto, sem considerar os custos envolvidos.

Dessa forma, este estudo deverá analisar a possibilidade e a viabilidade econômica (redução de custo) de se utilizar capacidade adicional de produção como forma de reduzir os estoques de segurança, necessários para garantir um determinado nível de serviço, num sistema sujeito a variações na demanda de um mix de itens, conforme a prática pioneira da Toyota citada por Hopp e Spearman (2004).

Além disso, este estudo diferencia-se dos demais por realizar a simulação de um sistema kanban, e não num cenário de produção empurrada tradicional. Conforme dito anteriormente, o sistema kanban é considerado ineficiente em cenários sujeitos a variações de demanda significativas e alto mix de produtos. Pode-se verificar ainda o quanto o uso de buffers de capacidade e estoque de segurança conferem maior flexibilidade ao sistema kanban, possibilitando bom desempenho mesmo com maiores níveis de variação. 


\section{Metodologia}

As pesquisas em gestão de operações freqüentemente utilizam a construção de modelos conceituais, considerando modelos como "uma abstração da realidade, no sentido de que a realidade completa não é incluída" (BERTRAND; FRANSOO, 2002, p.249). Algumas das variáveis que fazem parte da realidade acabam não sendo consideradas, de forma que alguns trade-offs essenciais tornem-se bastante explícitos, e os resultados estejam sujeitos a algum tipo de análise matemática.

Os autores destacam a possibilidade de se construírem modelos quantitativos, baseados em um conjunto de variáveis incluídas em um domínio específico, enquanto relações causais e quantitativas são definidas entre essas variáveis. Os modelos podem ser utilizados quando a realização de experimentos torna-se muito complicada em sistemas reais, especialmente pelo custo envolvido e pela dificuldade de se isolar impactos de variáveis que não sejam de interesse, o que também pode dificultar a interpretação dos resultados. Dentre os modelos quantitativos, os modelos de simulação são bastante flexíveis, permitindo a alteração dos parâmetros analisados, e por serem facilmente reproduzidos.

A construção de modelos envolve uma etapa preliminar de conceituação, em que o modelo é descrito em termos e conceitos já aceitos e presentes em publicações. Além disso, deve apoiar-se em uma pesquisa bibliográfica relacionada ao problema estudado, o que permite a visualização de lacunas no conhecimento existente. Com freqüência, os modelos construídos constituem variações de modelos e análises já realizadas apresentando, porém, "novas técnicas ou melhores soluções para problemas já conhecidos ou semelhantes” (BERTRAND; FRANSOO, 2002, p.255).

\section{Descrição do sistema}

O sistema a ser modelado apresenta as seguintes características:

a) Sistema composto por 1 estação de trabalho;

b) A duração dos turnos de trabalho poderá variar de 8 até 10 horas (2 horas extras diárias);

c) Sem restrições de matéria-prima;

d) Sem quebra de equipamentos;

e) Existe variação dos tempos de processo e tempos de setup, descritos distribuições triangulares; 
f) Uso de um sistema kanban de cartão simples (single-card) para controle da produção e estoques de produto acabado;

g) Os lotes de produção serão sempre correspondentes a um dia de demanda prevista (média) para cada item;

h) O tamanho dos pedidos dos clientes para cada item é constante;

i) A cada 10 dias, o nível de demanda será alterado, através da mudança do tempo entre chegadas de pedidos para cada item;

j) Mix de 10 produtos, cuja demanda é definida por uma distribuição triangular de mesmo valor central;

1) O custo dos estoques de segurança será de $\$ 1 /$ peça / dia;

m) O custo de capacidade de produção adicional será de $\$ 500$ / hora.

O dimensionamento dos supermercados será calculado em planilhas e, em seguida, estes parâmetros (demanda de cada item, nível de reposição, etc) serão transferidos para o modelo de simulação. O dimensionamento seguirá o método descrito por Tardin (2001), que corresponde ao calculo de três faixas de estoque, sempre proporcionais a demanda de cada item: verde, que corresponde ao lote de produção; amarela, que corresponde ao tempo para reposição dos estoques; e a vermelha, que é o estoque de segurança, e corresponde ao tempo de proteção desejado.

\section{Parâmetros do experimento}

Os experimentos serão realizados considerando os seguintes parâmetros:

a) O nível de demanda diária será definido por uma distribuição triangular, cujos extremos podem assumir valores entre $0 \%$ e $50 \%$ a mais do que o valor central, ou a menos do que o mesmo valor central;

b) O nível de utilização planejado será ajustado através da mudança da duração de cada período de trabalho; o tempo será modificado para que a utilização do sistema possua vários valores entre $100 \%$ e $80 \%$; o nível de utilização é calculado da seguinte forma:

\footnotetext{
Nível de Utilização Planejado = Tempo total de fabricação / Tempo disponível

$=($ Tempo de processo + Tempo de setup $) /$ Tempo disponível
} 
c) O nível de estoque de segurança será calculado de forma iterativa; o modelo será executado, avaliando-se o nível de serviço; o tamanho do estoque de segurança de cada item será aumentado no valor de um pedido, até que o nível de serviço seja maior ou igual a $99,9 \%$;

Assim, serão realizadas simulações em 25 cenários, além do cenário padrão cuja demanda será determinística (sem variação). Serão combinados diferentes níveis de variação de demanda e utilização da capacidade, até que os estoques de segurança garantam o nível de serviço definido. Todos os cenários a serem simulados são mostrados na tabela 1.

Tabela 1 - Cenários a serem simulados durante o experimento.

\begin{tabular}{|c|c|c|c|}
\hline $\begin{array}{l}\text { Cenário } \\
\text { Número }\end{array}$ & $\begin{array}{c}\text { Variação de } \\
\text { demanda }\end{array}$ & $\begin{array}{l}\text { Nivel de } \\
\text { utilização } \\
\text { planejada }\end{array}$ & $\begin{array}{c}\text { Estoque de segurança necessário } \\
\text { para garantir o nivel de serviço } \\
\text { definido }\end{array}$ \\
\hline 0 & $0 \%$ & $100 \%$ & 0 \\
\hline 1 & $10 \%$ & $80 \%$ & Definido iterativamente \\
\hline 2 & $10 \%$ & $85 \%$ & Definido iterativamente \\
\hline 3 & $10 \%$ & $90 \%$ & Definido iterativamente \\
\hline 4 & $10 \%$ & $95 \%$ & Definido iterativamente \\
\hline 5 & $10 \%$ & $100 \%$ & Definido iterativamente \\
\hline 6 & $20 \%$ & $80 \%$ & Definido iterativamente \\
\hline 7 & $20 \%$ & $85 \%$ & Definido iterativamente \\
\hline 8 & $20 \%$ & $90 \%$ & Definido iterativamente \\
\hline 9 & $20 \%$ & $95 \%$ & Definido iterativamente \\
\hline 10 & $20 \%$ & $100 \%$ & Definido iterativamente \\
\hline 11 & $30 \%$ & $80 \%$ & Definido iterativamente \\
\hline 12 & $30 \%$ & $85 \%$ & Definido iterativamente \\
\hline 13 & $30 \%$ & $90 \%$ & Definido iterativamente \\
\hline 14 & $30 \%$ & $95 \%$ & Definido iterativamente \\
\hline 15 & $30 \%$ & $100 \%$ & Definido iterativamente \\
\hline 16 & $40 \%$ & $80 \%$ & Definido iterativamente \\
\hline 17 & $40 \%$ & $85 \%$ & Definido iterativamente \\
\hline 18 & $40 \%$ & $90 \%$ & Definido iterativamente \\
\hline 19 & $40 \%$ & $95 \%$ & Definido iterativamente \\
\hline 20 & $40 \%$ & $100 \%$ & Definido iterativamente \\
\hline 21 & $50 \%$ & $80 \%$ & Definido iterativamente \\
\hline 22 & $50 \%$ & $85 \%$ & Definido iterativamente \\
\hline 23 & $50 \%$ & $90 \%$ & Definido iterativamente \\
\hline 24 & $50 \%$ & $95 \%$ & Definido iterativamente \\
\hline 25 & $50 \%$ & $100 \%$ & Definido iterativamente \\
\hline
\end{tabular}

Fonte: Autoria própria (2008)

Após as simulações, os dados deverão ser analisados comparando-se, para um mesmo nível de variação de demanda, a relação entre níveis de utilização e estoques de segurança (gráfico de utilização x estoques); dessa forma, o trade-off apresentado no triângulo de processo (KLASSEN; MENOR, 2007) poderá ser verificado.

Será analisado ainda se a utilização prevista da estação de trabalho, através da alteração do período de trabalho diário, é confirmada, e se existe impacto nos tempos de fila da estação de trabalho e do tempo de reposição dos estoques. 


\section{Modelo Operacional}

O sistema descrito anteriormente será representado através de um modelo de simulação utilizando o software Arena. O modelo é constituído por 4 blocos distintos. O bloco A é responsável por gerar e atender os pedidos dos clientes. Ele é constituído por 10 estruturas semelhantes, uma para cada um dos produtos existentes no sistema. Pedidos são criados por um módulo CREATE com um tempo entre chegadas definido, sendo atendidos desde que exista estoque disponível (módulo $D E C I D E$ ). Caso o pedido seja atendido, o estoque é reduzido (módulo ASSIGN). Em ambos os casos, pedido atendido ou perdido, a quantidade de pedidos é contabilizada por módulos RECORD.

O Bloco B define o tempo entre chegadas dos pedidos, o que faz com que a demanda de cada item varie ao longo do tempo. O tempo entre chegadas de cada um dos produtos é definido pela variável 'vChegadasProdX' (considerando que $X$ varia de 'a' até ' $j$ '), modelada por uma distribuição triangular (módulo $A S S I G N$ ). Quanto maior o nível de variação definido nos cenários da simulação, mais os tempos entre chegadas dos pedidos podem variar, o que pode levar a maiores mudanças na demanda. A demanda de cada item é redefinida a cada 10 dias (módulo CREATE gera uma entidade em intervalos constantes de 10 dias).

Já o Bloco $\mathrm{C}$ do modelo representa o processo de produção dos itens para reposição dos estoques, bem como o fluxo dos cartões kanban que autorizam essa produção. Para cada item, um módulo CREATE gera um cartão kanban no sistema. O recurso central (módulo PROCESS) representa a estação de trabalho, com existência de tempo de setup e tempo de processo variável, em função do tamanho do lote de produção. Módulos $A S S I G N$, aumentam os estoques de cada um dos itens, após a produção ser concluída. Os módulos $H O L D$ são responsáveis por limitar a quantidade de material em processo, de forma que a produção só é autorizada quando o ponto de disparo do sistema kanban é atingido, e os cartões retornam para o processo de produção através dos módulos ROUTE e STATION.

Por fim, o Bloco D do modelo apresenta os indicadores monitorados durante a simulação, mostrando o valor corrente de algumas variáveis do sistema. Cada um dos gráficos mostra o nível de estoque para cada produto, além do estoque de segurança e o estoque 'normal'.

\section{Modelo de custo}

Hopp e Spearman (2001) salientam que toda variação do sistema deve ser acomodada por algum tipo de proteção (buffer), e que isso, de forma inevitável, implica em custo e que quanto maiores os níveis de variação, maior o custo necessário para que essa seja acomodada. Dessa forma, 
pode-se verificar se o custo mínimo dos buffers, para cada nível de variação de demanda, realmente é crescente à medida que a variação aumenta. A seguir, segue a descrição de como a análise de custo será realizada.

O custo total da operação possui alguns componentes, podendo ser descrito pela expressão abaixo:

\section{Custo operacional total $=$ Custo total de capacidade de produção + Custo total de estoque}

Cada um dos componentes acima pode ser ainda desdobrado, da seguinte forma:

Custo total de capacidade de produção $=$ Custo de capacidade de produção nas horas normais + Custo de capacidade de produção nas horas adicionais

considerando que as 'horas normais' correspondem as 8 primeiras horas produtivas do dia, e que as 'horas adicionais' correspondem ao limite de 2 horas adicionais que podem ser trabalhadas diariamente, dependendo do cenário simulado. E ainda:

Custo total de estoque $=$ Custo de estoque normal + Custo de estoque de segurança considerando o 'estoque normal' como estoque verificado na simulação em ambiente determinístico, e que o 'estoque de segurança' existe somente em cenários onde existe variação da demanda.

Dessa forma, o custo operacional total também pode ser representado por:

Custo operacional total $=$ Custo de capacidade de produção nas horas normais + Custo de capacidade de produção nas horas adicionais + Custo de estoque normal + Custo de estoque de segurança

Quando o cenário padrão das simulações é considerado, verifica-se o custo operacional total mínimo, uma vez que não existe variação de demanda, não existem estoques de segurança e nem horas adicionais de produção. O custo mínimo é decorrente somente das 8 horas normais de capacidade, além do 'estoque normal' de cada item, utilizado para o atendimento da demanda.

Para todos os demais cenários considerados na simulação, os componentes 'normais' de custo ('custo de capacidade de produção nas horas normais' e 'custo do estoque normal') sempre estarão presentes, de forma que a análise e comparação de custo entre cada um dos cenários dependerá somente dos componentes 'não-normais', decorrentes da existência de variação de demanda, ou seja, 'custo de capacidade de produção nas horas adicionais' e 'custo de estoque de segurança'. Assim, pode-se dizer que o custo operacional gerado pela existência de variações, ou custo dos buffers necessários, pode ser descrito da seguinte forma: 
Custo dos buffers $=$ Custo de capacidade de produção nas horas adicionais + Custo de estoque de segurança

O custo dos buffers será calculado pelas seguintes expressões:

Custo do estoque de segurança $=$ Estoque de segurança médio no período $\mathrm{x}$ Custo manutenção dos estoques $x$ Dias considerados no período

e

Custo de capacidade de produção nas horas adicionais $=$ Horas adicionais utilizadas $\mathbf{x}$ Custo horário de capacidade adicional $x$ Dias considerados no período

Através destas análises, as hipóteses propostas através de triângulo de processo, descrito por Klassen e Menor (2007), poderão ser verificadas, além da proposta deste estudo, que é a análise do uso da capacidade como forma de se criarem buffers (alternativa ao estoque de segurança), além de sua viabilidade econômica.

Vale ressaltar que o custo das vendas perdidas não está sendo contabilizado, devido a sua mensuração ser subjetiva. Além disso, o fato de que o nível de serviço requerido é bastante elevado, de $99,9 \%$, faz com que as perdas sejam pouco significativas.

\section{Análise dos Resultados}

A Figura 3 mostra os gráficos de estoques de segurança x utilização para cada um dos níveis de variação de demanda. Pode-se verificar que o aumento da variação de demanda exige um maior estoque de segurança para acomodar essa incerteza. Verificou-se que o nível de serviço de 99,9\% não foi conseguido nos casos em que o nível de utilização planejado é de $100 \%$, ainda que o nível de estoque seja muito alto. Isso explica a ausência de pontos em algumas das curvas mostradas na figura 3. 
Figura 3 - Gráficos de Estoque de Segurança x Utilização para todos os níveis de variação de demanda.

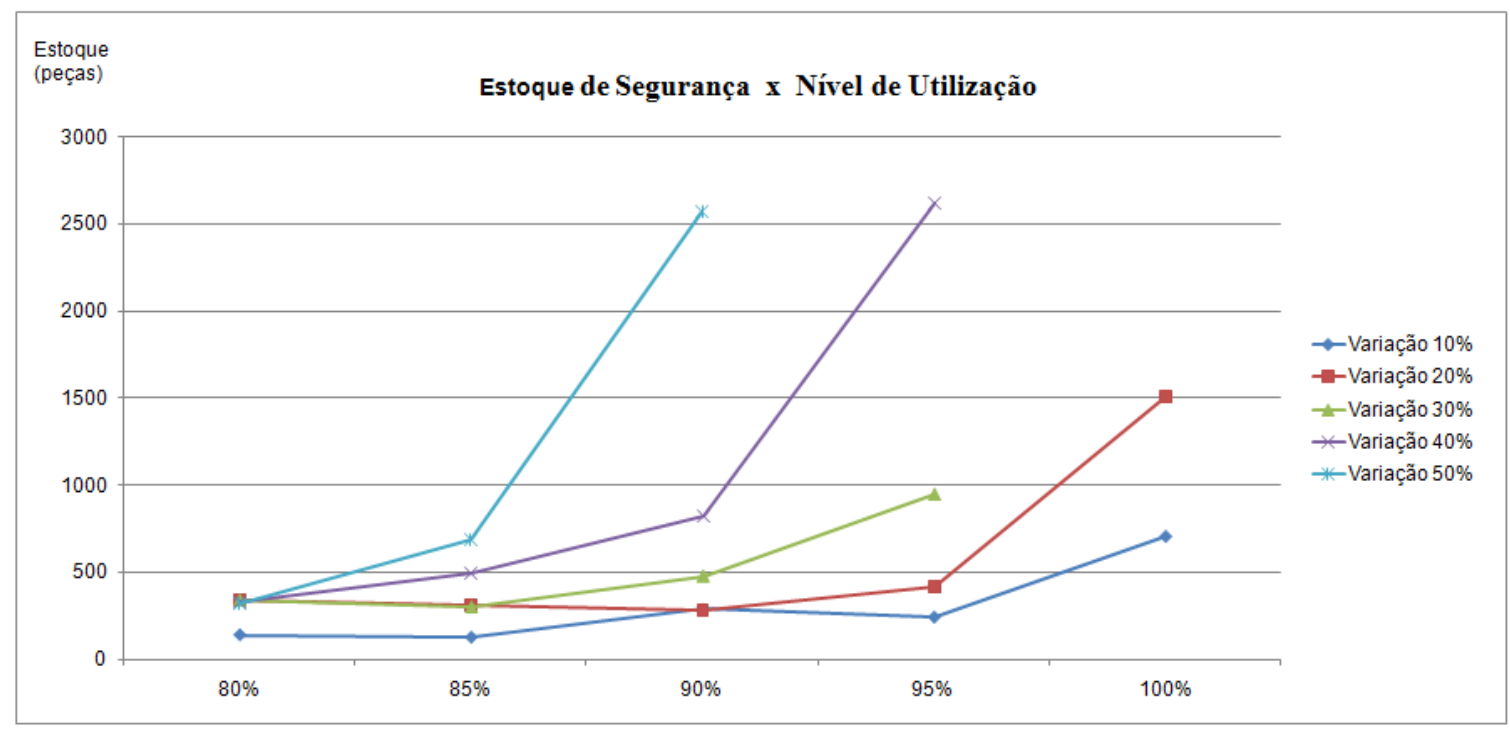

Fonte: Autoria própria (2008)

O trade-off entre capacidade de produção e estoque de segurança também pode ser visualizado na mesma figura. Todas as curvas mostram uma tendência crescente a medida que o nível de utilização aumenta.

Por fim, também pode ser observada na Tabela 2 a comparação entre o nível de utilização planejado (definido através do tamanho do período de trabalho) e a utilização média verificada após a execução dos modelos de simulação. Pode ser visto que, para os cenários em que os níveis de variação de demanda são pequenos, a utilização verificada é muito próxima a planejada, com desvio inferior a 1\%. Para cenários com as maiores variações, o desvio pode atingir quase 4\%. Apresentadas as variáveis de processo, a seguir as análises de custo de custo são realizadas, considerando os resultados das simulações apresentados na tabela 2 , as equações mostradas na seção 8, e os custos de estoques e de capacidade adicional para o sistema, descritos na seção 5. Os resultados são apresentados na tabela 3.

O período válido da simulação foi de 12 meses, dessa forma a última coluna a direita apresenta o custo total anual para cada um dos cenários, sendo constituído pela soma dos custos anuais de capacidade de produção adicional e de estoque de segurança. Para um mesmo nível de variação de demanda, pode-se observar que o aumento de capacidade pode trazer redução de custos, uma vez que os estoques de segurança são significativamente reduzidos. Para cada um dos níveis de variação, foram destacados os custos mínimos. Em nenhum dos casos, o custo mínimo foi verificado quando o nível de utilização atingiu 100\%. Pode-se verificar também que, quanto maiores os níveis de variação no sistema, mais capacidade foi utilizada para se conseguir o custo mínimo, e confirmando o argumento apresentado por Hopp e Spearman (2001), à medida que as 
variações no sistema aumentam, maiores os custos envolvidos para acomodar a variação. Os resultados mostrados na tabela 3 confirmam esta tendência, sendo apresentados também na figura 5 . De forma gráfica, a distância entre cada uma das curvas evidencia o fato.

A inversão de tendência, em determinado ponto, para cada uma das curvas confirma a existência do trade-off. Entretanto, as conclusões em termos de custo total podem ser alteradas, dependendo da relação entre o custo de capacidade e o custo do estoque de segurança. Essa mesma análise será realizada para um cenário onde o custo da capacidade é intensivo (o que ocorre em processos contínuos, siderúrgicos, etc, conforme citado anteriormente), cujo custo de estoque permanece o mesmo, mas o custo de capacidade é de $\$ 2500$ / hora. A figura 6 mostra o resultado.

Conforme mostrado na Figura 6, é interessante notar que, neste caso, o aumento da capacidade implica em aumento de custo, e que o custo dos estoques são muito menos relevantes. A mudança de comportamento das curvas que representam cada cenário é menos nítida, mostrando que, para este caso, não existe trade-off. Assim, maiores níveis de utilização dos recursos serão sempre vantajosos.

Tabela 2 - Resultados das simulações para cada cenário.

\begin{tabular}{|c|c|c|c|c|c|c|}
\hline $\begin{array}{l}\text { Cenário } \\
\text { Número }\end{array}$ & $\begin{array}{c}\text { Variação de } \\
\text { demanda }\end{array}$ & $\begin{array}{l}\text { Nivel de } \\
\text { utilização } \\
\text { planejada }\end{array}$ & $\begin{array}{c}\text { Estoque de } \\
\text { segurança } \\
\text { dimensionado }\end{array}$ & $\begin{array}{l}\text { Utilização } \\
\text { média } \\
\text { verificada }\end{array}$ & $\begin{array}{l}\text { Fila média em } \\
\text { processo } \\
\text { (horas) }\end{array}$ & $\begin{array}{c}\text { Estoque de } \\
\text { segurança } \\
\text { real }\end{array}$ \\
\hline 0 & $0 \%$ & $100 \%$ & 0 & $99,92 \%$ & 1,18 & 0 \\
\hline 1 & $10 \%$ & $80 \%$ & 0 & $80,17 \%$ & 0,71 & 147 \\
\hline 2 & $10 \%$ & $85 \%$ & 0 & $85,04 \%$ & 0,73 & 133 \\
\hline 3 & $10 \%$ & $90 \%$ & 200 & $90,19 \%$ & 0,86 & 292 \\
\hline 4 & $10 \%$ & $95 \%$ & 200 & $95,16 \%$ & 1,03 & 248 \\
\hline 5 & $10 \%$ & $100 \%$ & 1400 & $99,94 \%$ & 4,62 & 711 \\
\hline 6 & $20 \%$ & $80 \%$ & 200 & $80,41 \%$ & 0,73 & 339 \\
\hline 7 & $20 \%$ & $85 \%$ & 200 & $85,39 \%$ & 0,82 & 313 \\
\hline 8 & $20 \%$ & $90 \%$ & 200 & $90,88 \%$ & 0,89 & 284 \\
\hline 9 & $20 \%$ & $95 \%$ & 400 & $95,84 \%$ & 1,18 & 418 \\
\hline 10 & $20 \%$ & $100 \%$ & 3000 & $99,98 \%$ & 6,25 & 1516 \\
\hline 11 & $30 \%$ & $80 \%$ & 200 & $80,86 \%$ & 0,73 & 340 \\
\hline 12 & $30 \%$ & $85 \%$ & 200 & $86,64 \%$ & 0,87 & 299 \\
\hline 13 & $30 \%$ & $90 \%$ & 400 & $90,82 \%$ & 0,92 & 479 \\
\hline 14 & $30 \%$ & $95 \%$ & 1000 & $95,88 \%$ & 1,50 & 952 \\
\hline 15 & $30 \%$ & $100 \%$ & & & & \\
\hline 16 & $40 \%$ & $80 \%$ & 200 & $82,28 \%$ & 0,72 & 336 \\
\hline 17 & $40 \%$ & $85 \%$ & 400 & $86,79 \%$ & 0,85 & 502 \\
\hline 18 & $40 \%$ & $90 \%$ & 800 & $92,18 \%$ & 1,16 & 830 \\
\hline 19 & $40 \%$ & $95 \%$ & 3000 & $97,54 \%$ & 2,84 & 2619 \\
\hline 20 & $40 \%$ & $100 \%$ & & & & \\
\hline 21 & $50 \%$ & $80 \%$ & 200 & $83,66 \%$ & 0,78 & 325 \\
\hline 22 & $50 \%$ & $85 \%$ & 600 & $88,42 \%$ & 0,91 & 687 \\
\hline 23 & $50 \%$ & $90 \%$ & 2600 & $93,31 \%$ & 1,44 & 2571 \\
\hline 24 & $50 \%$ & $95 \%$ & & & & \\
\hline 25 & $50 \%$ & $100 \%$ & & & & \\
\hline
\end{tabular}

Fonte: Autoria própria (2008) 
Tabela 3 - Análise dos custos considerando as características do sistema e resultados das simulações.

\begin{tabular}{|c|c|c|c|c|c|c|c|}
\hline $\begin{array}{l}\text { Cenário } \\
\text { Número }\end{array}$ & $\begin{array}{c}\text { Variação de } \\
\text { demanda }\end{array}$ & $\begin{array}{l}\text { Nivel de } \\
\text { utilização } \\
\text { planejada }\end{array}$ & $\begin{array}{c}\text { Estoque de } \\
\text { segurança } \\
\text { real }\end{array}$ & $\begin{array}{l}\text { Horas } \\
\text { adicionais } \\
\text { diárias }\end{array}$ & $\begin{array}{l}\text { Custo anual de } \\
\text { capacidade de } \\
\text { produção adicional }\end{array}$ & $\begin{array}{l}\text { Custo anual } \\
\text { de estoque } \\
\text { de segurança }\end{array}$ & $\begin{array}{c}\text { Custo anual } \\
\text { total }\end{array}$ \\
\hline 0 & $0 \%$ & $100 \%$ & 0 & 0,00 & 0 & 0 & 0 \\
\hline 1 & $10 \%$ & $80 \%$ & 147 & 2,00 & 240.000 & 35.350 & 275.350 \\
\hline 2 & $10 \%$ & $85 \%$ & 133 & 1,41 & 169.200 & 31.951 & 201.151 \\
\hline 3 & $10 \%$ & $90 \%$ & 292 & 0,89 & 106.800 & 70.078 & 176.878 \\
\hline 4 & $10 \%$ & $95 \%$ & 248 & 0,42 & 50.400 & 59.568 & 109.968 \\
\hline 5 & $10 \%$ & $100 \%$ & 711 & 0,00 & 0 & 170.580 & 170.580 \\
\hline 6 & $20 \%$ & $80 \%$ & 339 & 2,00 & 240.000 & 81.437 & 321.437 \\
\hline 7 & $20 \%$ & $85 \%$ & 313 & 1,41 & 169.200 & 75.127 & 244.327 \\
\hline 8 & $20 \%$ & $90 \%$ & 284 & 0,89 & 106.800 & 68.122 & 174.922 \\
\hline 9 & $20 \%$ & $95 \%$ & 418 & 0,42 & 50.400 & 100.282 & 150.682 \\
\hline 10 & $20 \%$ & $100 \%$ & 1.516 & 0,00 & 0 & 363.761 & 363.761 \\
\hline 11 & $30 \%$ & $80 \%$ & 340 & 2,00 & 240.000 & 81.540 & 321.540 \\
\hline 12 & $30 \%$ & $85 \%$ & 299 & 1,41 & 169.200 & 71.820 & 241.020 \\
\hline 13 & $30 \%$ & $90 \%$ & 479 & 0,89 & 106.800 & 114.970 & 221.770 \\
\hline 14 & $30 \%$ & $95 \%$ & 952 & 0,42 & 50.400 & 228.406 & 278.806 \\
\hline 15 & $30 \%$ & $100 \%$ & & & & & \\
\hline 16 & $40 \%$ & $80 \%$ & 336 & 2,00 & 240.000 & 80.599 & 320.599 \\
\hline 17 & $40 \%$ & $85 \%$ & 502 & 1,41 & 169.200 & 120.595 & 289.795 \\
\hline 18 & $40 \%$ & $90 \%$ & 830 & 0,89 & 106.800 & 199.183 & 305.983 \\
\hline 19 & $40 \%$ & $95 \%$ & 2.619 & 0,42 & 50.400 & 628.454 & 678.854 \\
\hline 20 & $40 \%$ & $100 \%$ & & & & & \\
\hline 21 & $50 \%$ & $80 \%$ & 325 & 2,00 & 240.000 & 78.108 & 318.108 \\
\hline 22 & $50 \%$ & $85 \%$ & 687 & 1,41 & 169.200 & 164.971 & 334.171 \\
\hline 23 & $50 \%$ & $90 \%$ & 2.571 & 0,89 & 106.800 & 617.124 & 723.924 \\
\hline 24 & $50 \%$ & $95 \%$ & & & & & \\
\hline 25 & $50 \%$ & $100 \%$ & & & & & \\
\hline
\end{tabular}

Fonte: Autoria própria (2008)

Para cada caso situação, deverá existir uma relação entre o custo de capacidade e o custo dos estoques que irá definir a estratégia de operações, capaz de garantir um determinado nível de serviço ao mínimo custo.

Figura 5 - Custo anual x utilização quando o custo de capacidade é de \$500/hora.

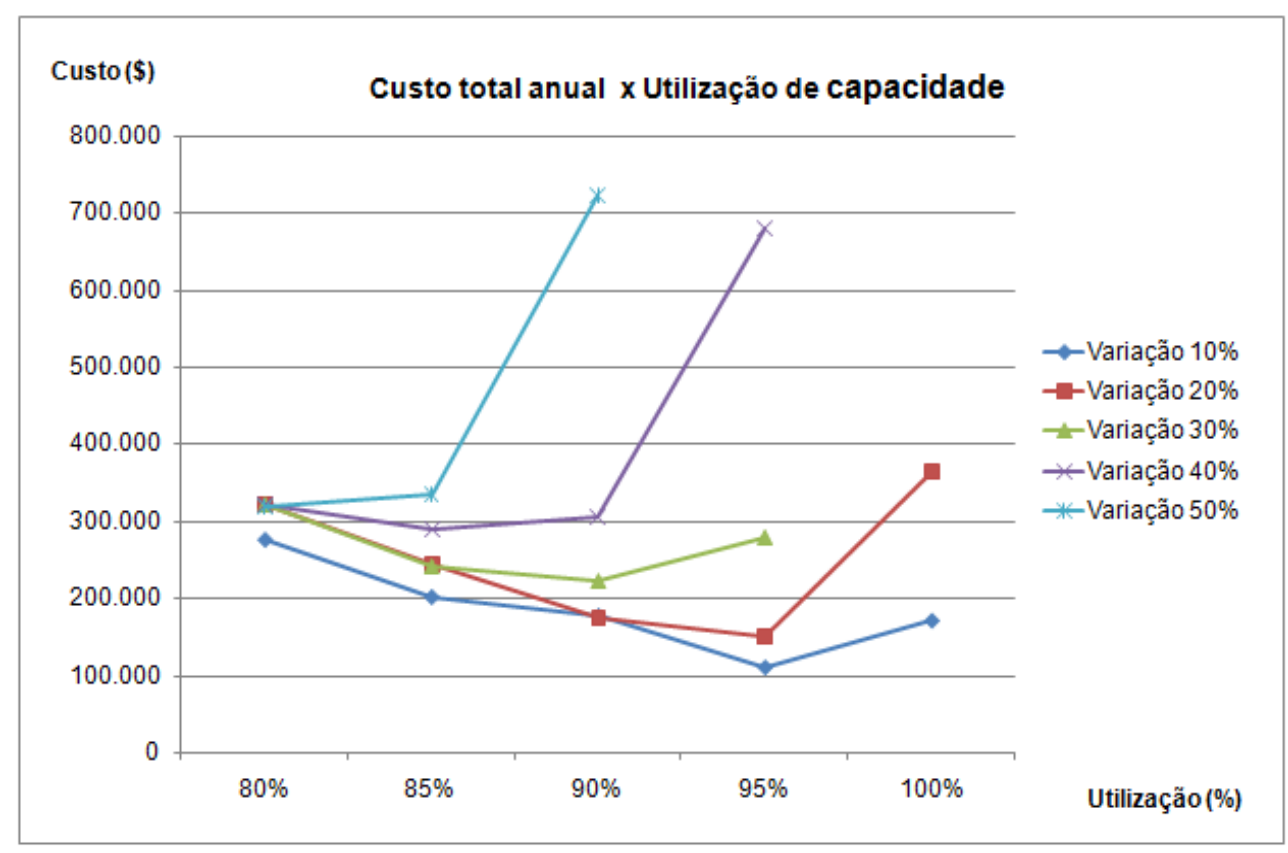

Fonte: Autoria própria (2008). 
Figura 6 - Custo anual x utilização quando o custo de capacidade é de \$2500/hora.

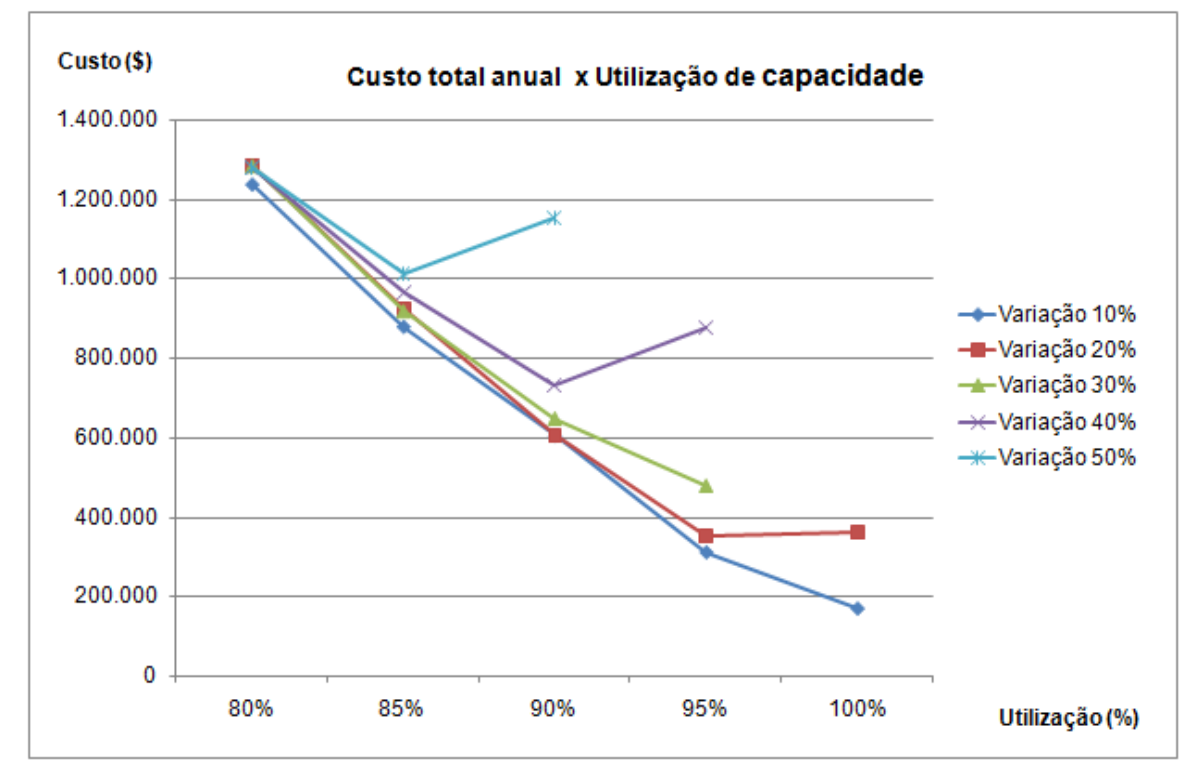

Fonte: Autoria própria (2008)

\section{Conclusões}

Realizadas as simulações, pôde-se concluir que, para maiores níveis de variação de demanda, mais buffers foram necessários para acomodar essa variação, o que acarreta em aumento dos custos, de acordo com a teoria exposta por Hopp e Spearman (2001). Verificou-se ainda que, operacionalmente, a disponibilidade de maior capacidade de produção (maior folga), de forma complementar aos estoques de segurança, permite a acomodação da maior variação de demanda e garante os níveis de serviço desejados, como citado por Klassen e Menor (2007), Garg et al. (2001) e Mapes (1993). Já em relação aos custos da operação, o aumento da capacidade pode ser desvantajoso em relação à redução dos estoques de segurança proporcionada. Para cada situação, existe uma relação entre cada componente de custo que pode tornar a alternativa preferível ou não, evidenciando o trade-off. Como previsto por Garg et al. (2001), em processos de custo de capacidade intensivo essa alternativa mostrou-se desvantajosa, podendo, entretanto, ser utilizada em processos em que o custo dos materiais é mais significativo.

Por fim, a análise realizada mostrou ainda que o sistema kanban pode ser utilizado de forma eficiente, mesmo sujeito a maiores variações na demanda, ao contrário do exposto por Monden (1981), Marek et al. (2001) e Takahashi et al. (2004), ainda que dependa de maior folga na capacidade de produção. O próprio sistema se ajustou aos novos níveis de demanda em cada período, alterando as freqüências de produção e reposição dos estoques. 


\begin{abstract}
This paper analyzes the trade-off between the cost to increase production capacity and the increase in safety stocks, required to assure an established service level to the client. Using a simulation model, developed with Arena software, it assesses the possibility of use this resources (capacity buffer and safety stocks) like substitutes in order to smooth demand variation in the system. At that study, the system is controlled by a kanban system with a single-stage production machine that produces a mix of ten products with demand variation through time. The result confirms the improvement in service level as capacity or safety stocks are increased, being the choice preferred defined by cost structure in each case.
\end{abstract}

Key-words: trade-off; inventory; capacity; simulation; buffer.

\title{
Referências
}

AKTURK, M.S.; ERHUN, F. An overview of design and operational issues of kanban systems. International Journal of Production Research, v.37, n.17, p. 3859-3881, 1999.

crossef

BERKLEY, B.J. A review of the kanban production control research literature. Production and operations management, v.1, n.4, p. 393-411, 1992.

cross ${ }^{\text {ref }}$

BERTRAND, J.W.M.; FRANSOO, J.C. Operations management research methodologies using quantitative modeling. International Journal of Operations e Production Management, v.22, n.2, p. 241-264, 2002.

cross ${ }^{\text {ref }}$

DUGGAN, K. Creating mixed model value streams: Practical lean techniques for building to demand. New York: Productivity Press, 2002.

FERNANDES, F.C.F.; MACCARTHY, B.L. A multi-dimensional classification of production systems for the design and selection of production planning and control systems. Production Planning and Control, v.11, n.5, p. 481-496, 2000 .

cross ref

GARG, S.; VRAT, P.; KANDA, A. Equipment flexibility vs. inventory: a simulation study of manufacturing systems. International Journal of Production Economics, n.70, p. 123-145, 2001.

HOPP, W.J.; SPEARMAN, M.L. Factory Physics: Foundations of Manufacturing Management. Boston: Irwin/McGraw-Hill, 2001.

crossef

HOPP, W.J.; SPEARMAN, M.L. To pull or not to pull: What's the question. Manufacturing e Service Operations Management, v.6, n.2, p. 133-148, 2004.

cross ref

HUANG, C.; KUSIAK, A. Overview of Kanban systems. International Journal of Computer Integrated Manufacturing, v.9, n.3, p. 169-189, 1996.

cross ref

HURLEY, S.F.; WHYBARK, D.C. Inventory and capacity trade-offs in a manufacturing cell. International Journal of Production Economics, v.59, p. 203-212, 1999.

cross ref

KLASSEN, R.; MENOR, L. The process management triangle: An empirical investigation of process trade-offs. Journal of Operations Management, v.25, p. 1015-1034, 2007.

cross ref 
KUMAR, C.S.; PANNEERSELVAM, R. Literature review of JIT-Kanban system. International Journal of Advanced Technology, n.32, p.393-408, 2007.

MAPES, J. The effects of capacity limitations on safety stock. International Journal of Operations and Production Management, v.13, p.26-33, n.10, 1993.

MAREK, R.P.; ELKINS, D.A.; SMITH, D.R. Understanding the fundamentals of kanban and conwip pull systems using simulation. PROCEEDINGS OF THE 2001 WINTER SIMULATION CONFERENCE.

MONDEN, Y. Adaptable Kanban system helps Toyota maintain just-in-time production. Industrial Engineering. v.13, n.5, p. 29-46, 1981.

SIPPER, D.; BULFIN, R.L. Production: Planning, Control and Integration. Singapore: McGraw-Hill, 1997.

TAKAHASHI, K.; MORIKAWA, K.; NAKAMURA, N. Reactive JIT ordering system for changes in the mean and variance of demand. International Journal of Production Economics, v.92, p. 181-196, 2004.

cross ref

TARDIN, G.G. O sistema puxado e o nivelamento da produção. 2001. 111 f. Dissertação (Mestrado em Engenharia Mecânica) - Faculdade de Engenharia Mecânica, Universidade Estadual de Campinas, Campinas.

VOLLMANN, T.; BERRY, W.; WHYBARK, D.; JACOBS, F. Sistemas de planejamento e controle da produção para o gerenciamento da cadeia de suprimentos. Porto Alegre: Bookman, 2006.

Dados dos Autores:

Luiz Guilherme Sandrini

Universidade de São Paulo

Escola Politécnica - Engenharia de Produção

Mestrando

Endereço para correspondência: Alameda Grajaú, 584 - Ap 44 - Alphaville - Barueri - SP 06454-050

Telefone para contato: (11) 8787-8700

E-mail: lgsandrini@yahoo.com.br

Prof. Dr. Marco Aurélio de Mesquita

Universidade de São Paulo

Escola Politécnica - Departamento de Engenharia de Produção

Endereço para correspondência: Av. Prof. Almeida Prado, trav. 2, n. 128 Cidade Universitária, São

Paulo - SP - 05508-070

Telefone para contato: (11) 3091-5363 r.462

E-mail: marco.mesquita@poli.usp.br 
